\title{
Validation and Joint Inversion of Teleseismic Waveforms for Earthquake Source Models Using Deep Ocean Bottom Pressure Records: A Case Study of the 2006 Kuril Megathrust Earthquake
}

\author{
Toshitaka Baba, ${ }^{1,2}$ Phil R. Cummins, ${ }^{2}$ Hong Kie Thio, ${ }^{3}$ and Hiroaki Tsushima ${ }^{4}$
}

\begin{abstract}
The importance of accurate tsunami simulation has increased since the 2004 Sumatra-Andaman earthquake and the Indian Ocean tsunami that followed it, because it is an important tool for inundation mapping and, potentially, tsunami warning. An important source of uncertainty in tsunami simulations is the source model, which is often estimated from some combination of seismic, geodetic or geological data. A magnitude 8.3 earthquake that occurred in the Kuril subduction zone on 15 November, 2006 resulted in the first teletsunami to be widely recorded by bottom pressure recorders deployed in the northern Pacific Ocean. Because these recordings were unaffected by shallow complicated bathymetry near the coast, this provides a unique opportunity to investigate whether seismic rupture models can be inferred from teleseismic waves with sufficient accuracy to be used to forecast teletsunami. In this study, we estimated the rupture model of the 2006 Kuril earthquake by inverting the teleseimic waves and used that to model the tsunami source. The tsunami propagation was then calculated by solving the linear long-wave equations. We found that the simulated 2006 Kuril tsunami compared very well to the ocean bottom recordings when simultaneously using P and long-period surface waves in the earthquake source process inversion.
\end{abstract}

Key words: Earthquake, tsunami, Kuril subduction zone, waveform inversion.

\section{Introduction}

The vast majority of large teletsunami are generated by undersea earthquakes. Because these earthquakes generate seismic waves which travel much faster than the tsunami, it is possible to develop a warning system based on the use of the seismic waves to detect a potentially tsunamigenic earthquake well before the arrival of the tsunami at shores distant from the earthquake epicenter. In practice, the magnitude and location of an earthquake are used to infer whether there is the potential for generation of a large tsunami, in which case a warning is initiated and sea-level data are monitored to confirm

\footnotetext{
${ }^{1}$ Research Program for Plate Dynamics, Institute for Research on Earth Evolution, Japan Agency for Marine-Earth Science and Technology, 3173-25 Showa-machi, Kanazawa-ku, Yokohama 236-0001, Japan.

${ }^{2}$ Geoscience Australia, GPO Box 378, Canberra ACT 2601, Australia. E-mail: phil.cummins@ga.gov.au

3 URS Group Inc., 556 El Dorado Street, Pasadena, California 91101, USA.

4 Research Center for Prediction of Earthquakes and Volcanic Eruptions, Tohoku University, 6-6 AzaAoba, Aramaki, Aoba-ku, Sendai 980-8578, Japan.
} 
whether or not a large tsunami has actually been generated. To our knowledge, more detailed seismic information about the properties of the earthquake that generated the tsunami, such as its slip distribution, is not currently used operationally in any tsunami warning system.

While teletsunami amplitudes are not expected to be strongly influenced by details of the slip distribution on the earthquake fault (GeIst and DMowsKA, 1999), recent events have shown that there are important exceptions to this general rule. Events such as the $\mathrm{M}_{\mathrm{w}}=9.3$ (SteIN and OKaL, 2007) Sumatra-Andaman earthquake of 2004, with a fault length of over $1200 \mathrm{~km}$ (see Ammon et al., 2005 and CHLieH et al., 2007, among others), are so large that coastlines even $1,000 \mathrm{~km}$ distant from the earthquake are still within a fault length's distance from the rupture area and may therefore experience tsunami heights that are sensitive to the spatial distribution of fault slip. Even for smaller events, slip may be concentrated at depth on the megathrust, as in the $\mathrm{M}_{\mathrm{w}}=8.7$ Nias earthquake of 28 March, 2005 (e.g., BRIGGs et al., 2006), or it may be concentrated at shallow depth near the trench, as in the $\mathrm{M}_{\mathrm{w}}=7.8$ Java earthquake of 17 July, 2006 (Ammon et al., 2006). In such cases, the resulting tsunami may be much smaller or larger, respectively, than would be expected based on estimates of the earthquake magnitude alone. At least in cases such as these, detailed fault slip models would seem to be useful in modelling tsunami waveforms.

With recent advances in the number of seismographic stations telemetering data in real time, detailed seismic models of the earthquake source can potentially be obtained soon after an earthquake has occurred. This may allow rapid tsunami modelling to be performed that can contribute to tsunami warning information disseminated to potentially affected coastlines. There are many questions that need to be answered before such modelling can be utilized in the operation of a tsunami warning center. One fundamental question which this paper seeks to answer is: Can seismic data provide sufficiently accurate models of the slip distributions of large tsunamigenic earthquakes to be reliably used in teletsunami modelling? While both seismic (KiKUCHI and KANAMORI, 1991) and tsunami (SATAKE, 1987) data are routinely used separately to estimate slip distributions for large earthquakes, they are rarely used together (see, however, SATAKE, 1993; TANIOKA et al., 1995; Johnson et al., 1996; Konca et al., 2007; SATAKE and TANIOKA, 1995; Delouis et al., 2002; KoKetsu et al., 2004; ICHINOSE et al., 2005 and СHLieH et al., 2007, for examples of joint inversion using various combinations of seismic, tsunami and geodetic data). One reason for this is that tsunami data have hitherto been taken from coastal tide gauges, which can be very sensitive to the shallow bathymetry in their immediate vicinity. This makes it very difficult to judge whether any discrepancy between observed tsunami waveforms and those predicted based on a fault slip model is due to an inaccuracy in the model, or to inaccurate (or poorly modelled) bathymetry. This situation has changed in recent years with the deployment of a network of ocean bottom pressure recorders (BPRs) in the Pacific Ocean, which record tsunami waveforms in the deepocean where they are less sensitive to small variations in bathymetry.

In this paper we consider the use of seismic data for determining the slip distribution of a magnitude 8.3 Kuril earthquake that occurred on 15 November, 2006. This 
earthquake was the first large tsunamigenic earthquake to occur in the northern Pacific Basin since the establishment of networks of BPRs. Seismic body- and surface-wave data are used to estimate slip models for the earthquake, and these slip models are used to generate seafloor displacement that is used as an initial condition for tsunami propagation. The computed tsunami waveforms are then compared with data recorded by the BPRs to determine whether the seismic slip models are sufficiently accurate to be used in modelling teletsunami waveforms.

\section{Seismic and Tsunami Observations of the 15 November, 2006 Kuril Islands Earthquake}

As estimated by the USGS's National Earthquake Information Center (NEIC), the 15 November, 2006 Kuril Islands earthquake occurred at 11:14:16 UTC, with hypocentral parameters as indicated in Table 1. Although the earthquake caused no fatalities, it generated a teletsunami which injured one person in Hawaii and caused damage in Crescent City, California. Also listed in Table 1 are the Centroid Moment Tensor (CMT) estimates made by the NEIC and the Global CMT Project. Since both moment tensor solutions indicate a shallow thrust event, we assumed that this earthquake ruptured along the boundary between the subducting Pacific Plate and the North American Plate. Therefore, rather than adopting the strike and dip of either of the moment tensor solutions from Table 1 , we used the strike of the Kuril Trench, $220^{\circ}$, and a dip, $10^{\circ}$, defined as the average dip of the plate boundary determined in a marine seismic survey of the Kuril Trench (NAKANISHI et al., 2004). We assumed that rupture occurred over a $400 \times 140 \mathrm{~km}^{2}$ area of this fault plane, with its upper edge along the trench axis. In the modelling of seismic waves and tsunami described below, we have divided this rupture surface into $20 \times 20 \mathrm{~km}^{2}$ square subfaults, with 20 subfaults along strike and 7 down the dip of the rupture area.

\subsection{Seismic Data}

Due to their relatively short wavelengths, seismic body waves have more potential to resolve spatial details of earthquake fault slip patterns than do surface wave or tsunami

Table 1

Source parameters for the 15 November, 2006 Kuril earthquake

\begin{tabular}{llllcrrr}
\hline Source & Lat. $\left({ }^{\circ} \mathrm{N}\right)$ & Lon. $\left({ }^{\circ} \mathrm{E}\right)$ & Depth $(\mathrm{km})$ & Strike $\left(^{\circ}\right)$ & $\operatorname{Dip}\left(^{\circ}\right)$ & $\operatorname{Rake}\left({ }^{\circ}\right)$ & $\mathrm{M}_{\mathrm{w}}$ \\
\hline NEIC Hypocenter & 46.61 & 153.23 & 30 & - & - & - & - \\
NEIC MT & 46.68 & 153.22 & 7 & 270 & 16 & 121 & 7.9 \\
Global CMT & 46.75 & 154.32 & 13 & 214 & 15 & 92 & 8.3 \\
This study & 46.68 & 153.22 & 20 & 220 & $10^{1}$ & $90 \pm 45$ & 8.4 \\
\hline
\end{tabular}

Fault geometry parameters obtained from azimuth of trench axis and the seismic velocity model of NAKANISHI et al. (2004) 
(a)

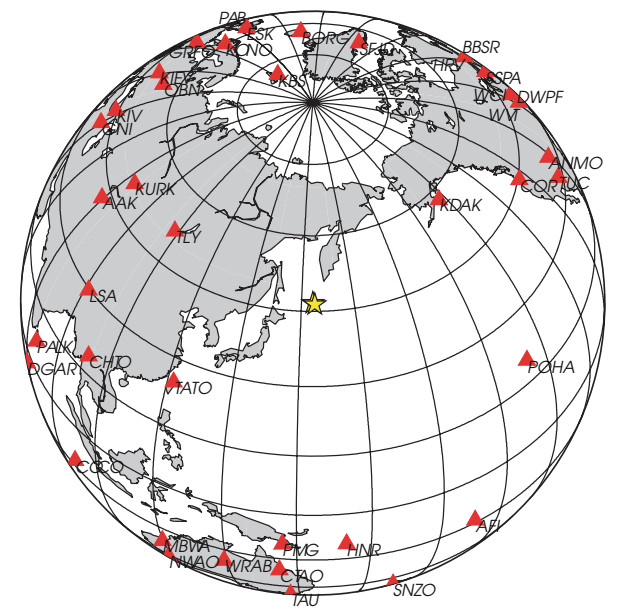

(b)

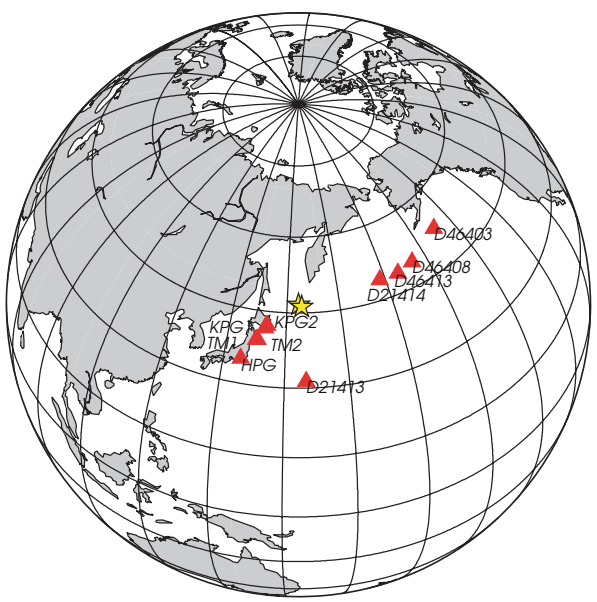

Figure 1

Geographic distribution of stations (triangles) that recorded observations of the 2006 Kuril earthquake used in this study: (a) Seismic stations, (b) ocean-bottom pressure (tsunami) gauges. Stars show location of the epicenters of the 2006 and 2007 Kuril earthquakes.

data. However, inversions for fault slip using only body-wave data may be less stable than those which use longer-wavelength data such as surface-wave or tsunami data. In this study we consider the use of surface-wave and body-wave data, both independently and jointly, to investigate the issue of stability vs. resolution. We downloaded the available GSN (Global Seismological Network) data from the Data Management Center of the Incorporated Research Institutions for Seismology. The seismic stations whose data were used to estimate the earthquake slip distribution are shown in Figure 1a. We have avoided stations closer than $30^{\circ}$ and greater than $90^{\circ}$ from the epicentre, to avoid waveforms which are sensitive to upper mantle structure or contain diffracted energy, respectively. All records had the instrument response removed via a 'water-level' deconvolution.

The 25 vertical $\mathrm{P}$ waveforms used in the inversion were bandpasss-filtered to remove energy outside the $4 \mathrm{mHz}$ to $4 \mathrm{~Hz}$ passband. The time window used for the P-wave analysis was taken to include $190 \mathrm{sec}$ after the arrival of the $\mathrm{P}$ wave. Following the method of KiKUCHI and KANAMORI (1991), point-source P-wave Green's functions are calculated for the center of each subfault using the Haskell propagator matrix method of Bouchon (1976), which accounts for crustal structure and depth phases near the source. The observed P-wave arrivals are aligned with those on the synthetics to remove any travel-time anomalies due to laterally heterogeneous velocity structure along the sourcereceiver paths. Thus, the slip pattern obtained through $\mathrm{P}$-wave analysis is constrained relative to the earthquake epicentre. 
For surface waves, 24 Rayleigh and 22 Love waves were bandpass-filtered from 3.0 to $6.0 \mathrm{mHz}$, with a varying analysis window that depended on distance via Rayleigh and Love wave phase velocities appropriate for the $3.0-6.0 \mathrm{mHz}$ passband. Point-source surface wave synthetics were calculated for each subfault using the method of KANAMORI and STEWART (1976) including phase velocity corrections for 3-D structure (EKSTRÖM et al., 1997). No arbitrary shifts are applied to the surface wave data, so that they do constrain the absolute position of slip pattern.

The near-source seismic velocity structure used for both body- and surface-wave calculations was based on a marine seismic survey result performed in the southern Kuril subduction zone (NAKANISHI et al., 2004).

\subsection{BPR Tsunami Data}

The locations of the BPRs used in this study are shown in Figure 1b. We downloaded data from Deep Assessment and Reporting of Tsunamis (DART, see e.g. Titov et al., 2005) buoys in the northeastern Pacific, as well as from seafloor cable BPRs (HIRATA et al., 2002; IwASE et al., 2003) off Japan, from the web sites http://nctr.pmel.noaa.gov/ Dart/ and http://www.jamstec.go.jp/scdc/top_e.html, respectively. We also used BPR data from other cable systems off Japan (TM1 and TM2, see Fig. 1b) operated by Tohoku University (Kanazawa and HaSEgawa, 1997). These instruments record pressure fluctuations caused by phenomena such as ocean tides, seismic waves and vertical displacement at the seafloor as well as tsunami. In order to remove the non-tsunami signals from the data, we used a data processing procedure similar to that of HIRATA et al. (2003). In the tsunami frequency band, BPR pressure data are converted to sea-surface disturbances via $\Delta \mathrm{P}=\rho \mathrm{g} \Delta \mathrm{h}$, where $\Delta \mathrm{P}$ is water pressure fluctuation, $\rho$ is the density of seawater $\left(1.0 \mathrm{gm} / \mathrm{cm}^{3}\right), \mathrm{g}$ is the gravitational acceleration at the earth's surface $\left(9.8 \mathrm{~m} / \mathrm{s}^{2}\right)$, and $\Delta \mathrm{h}$ is sea-level fluctuation. Short-period components such as pressure vibrations related to Rayleigh waves were removed by applying a block mean filter with a width of $100 \mathrm{sec}$ to the original records (Fig. 2b). The theoretical tide at each BPR location was calculated using the Naotide software (МАтsumото et al., 2000) and was subtracted from the block-mean filtered data. Because some residual tidal signal remains after removing the theoretical tide, we also applied a high-pass filter with a corner frequency of $120 \mathrm{~min}$, after which the dominant signal on all recordings was the tsunami. The first-arriving tsunami wave with a height of about $2.5 \mathrm{~cm}$ can be seen at KPG1 in Figure 2c.

For modelling the BPR data, we used finite-difference tsunami modelling software developed by Satake (1995), which solves the linear longwave equation including the Coriolis force. The tsunami computation area was defined from $120 \mathrm{E}$ to $220 \mathrm{E}$ and $15 \mathrm{~N}$ to $65 \mathrm{~N}$ to contain the ocean-bottom pressure gauges shown in Figure 1b. The bathymetric grid data with an interval of 2' was created by re-sampling the GEBCO bathymetry dataset (http://www.ngdc.noaa.gov/mgg/gebco/grid/1 mingrid.html) in order to save computation time. Total grid points are $3000 \times 1500$ points. The time step used in the computation was $3 \mathrm{sec}$ in order to satisfy the stability condition of the finite- 


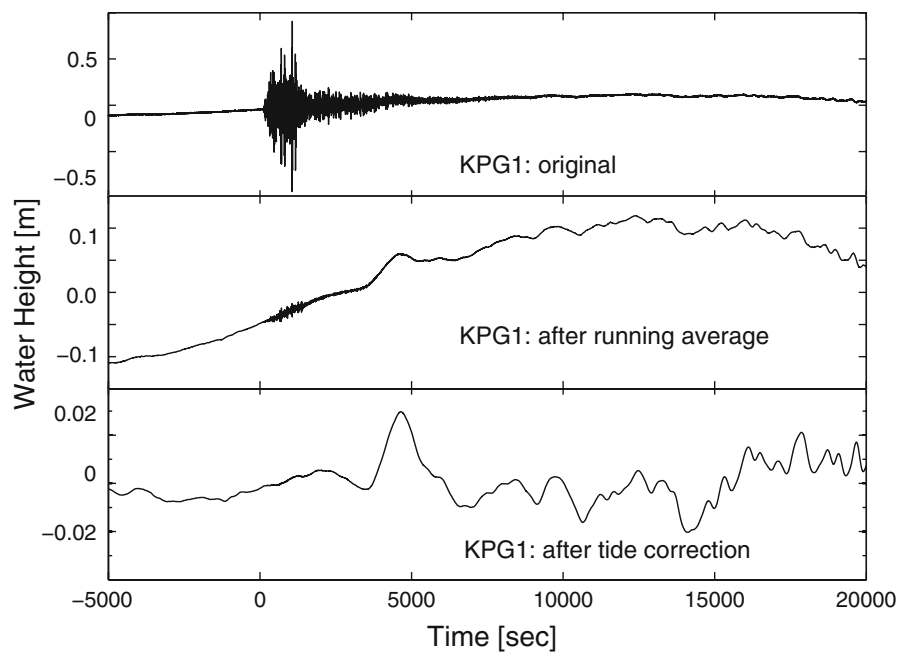

Figure 2

(a) Original water pressure fluctuation recorded at KPG1. The short-period disturbance due to seismic waves is seen. (b) After removal of the short-period components by a block mean filter. (c) Tsunami waveforms are retrieved after removal of the long-period ocean tide components.

difference scheme. The tsunami initial condition is assumed to be equal to the vertical ocean bottom deformation due to the faulting, which was computed using the equations of OKADA (1985).

\section{Inversion of Seismic Data for the 2006 Kuril Earthquake and Comparison with Deep-ocean BPR Data}

We employed an inversion to determine the temporal and spatial distribution of slip on the fault plane. Both surface and body waves were inverted for fault slip using the multiple-time window algorithm of Тніо et al. (2004), which is a modified form of the slip inversion method developed by Hartzell and Heaton (1983). This method involves the construction of the normal equations:

$$
\left(\begin{array}{c}
C_{d}^{-1} A \\
\lambda_{1} S \\
\lambda_{2} M
\end{array}\right) x=\left(\begin{array}{c}
C_{d}^{-1} b \\
0 \\
0
\end{array}\right) .
$$

The elements of matrix A consist of Green's functions of seismic waves for body and/ or surface waves, calculated as discussed above by using unit slip point sources at the center of each subfault, $\mathbf{S}$ is a matrix of smoothing constraints and $\mathbf{M}$ is a minimization criterion. $\lambda_{1}$ and $\lambda_{2}$ are hyperparameters which weight the smoothing and minimization criteria, respectively, and were chosen by trial and error as the maximum weights that did not significantly degrade the fit to the observed waveforms. Finally, $C_{d}$ is a data 
covariance matrix. Following HARTzell and LANGer (1993) we use a diagonal matrix whose values are such that each trace in the vector $b$ will have a peak value of 1 . Thus, when body- and surface-wave data, and later tsunami data, are inverted simultaneously, they are all included with normalized amplitude, and no attempt was made to use any other relative weighting for the different datasets.

A least-squares inversion with positivity constraint is applied to the normal equations (1) using the Houselholder reduction method of LAwsON and HANson (1974). As discussed by HARTZELl and LANGer (1993), among others, the positivity constraint is needed to prevent instability in the inversion, which may manifest itself in adjacent subfaults taking on equal and opposite slips. The rake angle of the slip was allowed to vary, however, within the range $90 \pm 45$ degrees.

The subfault underlying the epicenter determined by the USGS (Table 1) was used as the starting point for rupture in the inversion. The maximum speed of rupture propagation was assumed to be $1.8 \mathrm{~km} / \mathrm{sec}$, and each subfault was permitted to slip over $30 \mathrm{sec}$ after the passing of rupture front. The slip on each subfault was parameterized with triangles of $5.0 \mathrm{sec}$ half-width, so that each subfault could slip over 5 time steps of $5.0 \mathrm{sec}$ duration, allowing for some variation in rupture velocity. The time step and triangle half-width were chosen to match the frequency content of the observed P-waves, and the assumption of $1.8 \mathrm{~km} / \mathrm{sec}$ maximum rupture velocity was tested using the match of observed and predicted tsunami data described below.

\subsection{Inversion of Seismic P-Waves}

We first carried out a slip inversion using only direct P-wave data. The obtained cumulative slip distribution is shown in Figure 3a. An area of high slip appears in an "L-shape" pattern extending about $140 \mathrm{~km}$ to the northeast and mainly down-dip from the hypocenter. The maximum slip is $5.0 \mathrm{~m}$. The total seismic moment obtained is $5.20 \times 10^{21} \mathrm{Nm}\left(\mathrm{M}_{\mathrm{w}} 8.4\right)$, which is larger than that estimated by the Global CMT project $\left(3.4 \times 10^{21} \mathrm{Nm}\right)$. The variance reduction $(\mathrm{VR})$ of the $\mathrm{P}$ waves determined by $(1-$ $\left.\Sigma\left(\mathrm{d}_{\text {obs }}-\mathrm{d}_{\mathrm{cal}}\right)^{2} / \Sigma \mathrm{d}_{\mathrm{obs}}^{2}\right)$ is $67 \%$, where $\mathrm{d}_{\mathrm{obs}}$ and $\mathrm{d}_{\text {cal }}$ indicate normalized observed and calculated waveforms, respectively. We also independently calculated the synthetic surface waves derived from the obtained source model and obtained the VR value of 56\% for the surface waves (Table 2).

The predicted tsunami waveforms are shown in Figure $3 \mathrm{~b}$. The arrivals of the computed tsunami are about 2 or 3 min earlier, and the amplitudes are slightly smaller than these of the observed waveforms for the Japanese pressure gauges (KPG1, KPG2, TM1, TM2, HPG). We can see a second small peak (shown by arrows in Fig. 3b) on the observed tsunami records at KPG1, KPG2, TM1 and TM2, which is not reproduced in the simulation. The waveform fits for the DART stations (D21424, D46413, D46408 and D46403) are worse; the period of the computed tsunami is inconsistent with the observed waveforms. The first peaks of the computed tsunami are earlier than observed ones by several minutes. The VR of the tsunami waveforms was calculated to be $60 \%$. 
(a)
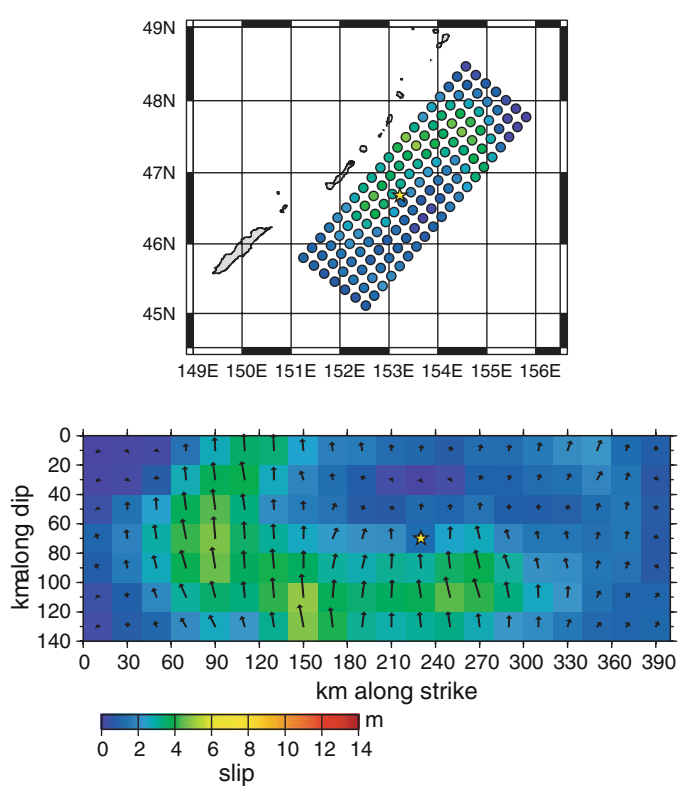

(b)
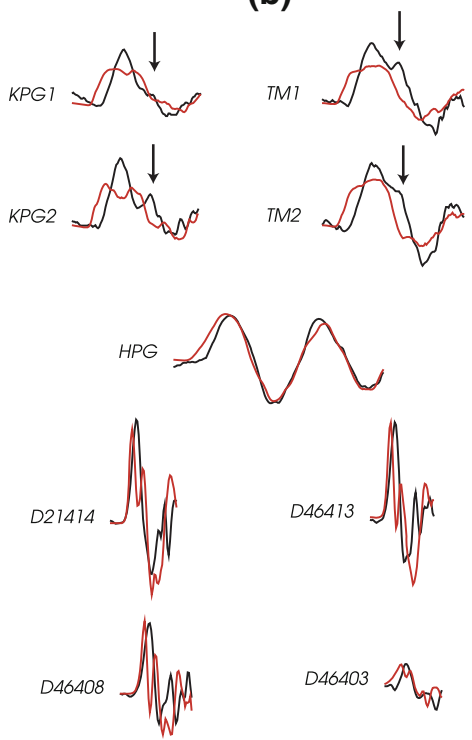

D46403

Figure 3

(a) Cumulative slip distribution of the 2006 Kuril earthquake estimated from the inversion of $\mathrm{P}$ waves only. The colour shows the slip amount and arrows represent the motion of hanging wall relative to footwall. The star denotes the hypocenter. (b) Comparison of the deep-ocean tsunami waveforms. Black and red lines show the observed and predicted tsunami waveforms, respectively, with the latter calculated from the slip model shown in

(a). The small second peaks on the tsunami record (shown by arrows) are not produced by the simulation.

Table 2

Parameters describing slip models obtained using different combinations of P-wave, surface wave, BPR tsunami waveform data, and corresponding variance reductions

\begin{tabular}{lllllll}
\hline Data types used & $\begin{array}{l}\text { Max. Slip } \\
(\mathrm{m})\end{array}$ & $\begin{array}{l}\text { Moment } \\
\left(\times 10^{21} \mathrm{Nm}\right)\end{array}$ & $\begin{array}{l}\text { P wave } \\
\text { VR }(\%)\end{array}$ & $\begin{array}{l}\text { Surface } \\
\text { VR }(\%)\end{array}$ & $\begin{array}{l}\text { BPR Tsunami } \\
\text { VR }(\%)\end{array}$ & $\begin{array}{l}\text { Total VR } \\
(\%)\end{array}$ \\
\hline P wave only & 5.0 & 5.20 & 67 & 56 & 60 & 61 \\
P wave and surface wave & 12.8 & 5.33 & 58 & 84 & 73 & 73 \\
$\begin{array}{l}\text { P wave, surface wave, } \\
\text { and BPR tsunami }\end{array}$ & 11.8 & 5.01 & 58 & 84 & 81 & 74 \\
\hline
\end{tabular}

\subsection{Inversion of Seismic P-Waves and Surface Waves}

The slip distribution obtained by using both $\mathrm{P}$ wave and long-period surface waves is quite different from the P-wave only model (Fig. 4a). The patch of highest slip is located near the trench just east of the epicenter. The maximum slip has increased to $12.8 \mathrm{~m}$. A separate area of smaller slip is imaged farther down-dip. The total seismic moment is 
(a)
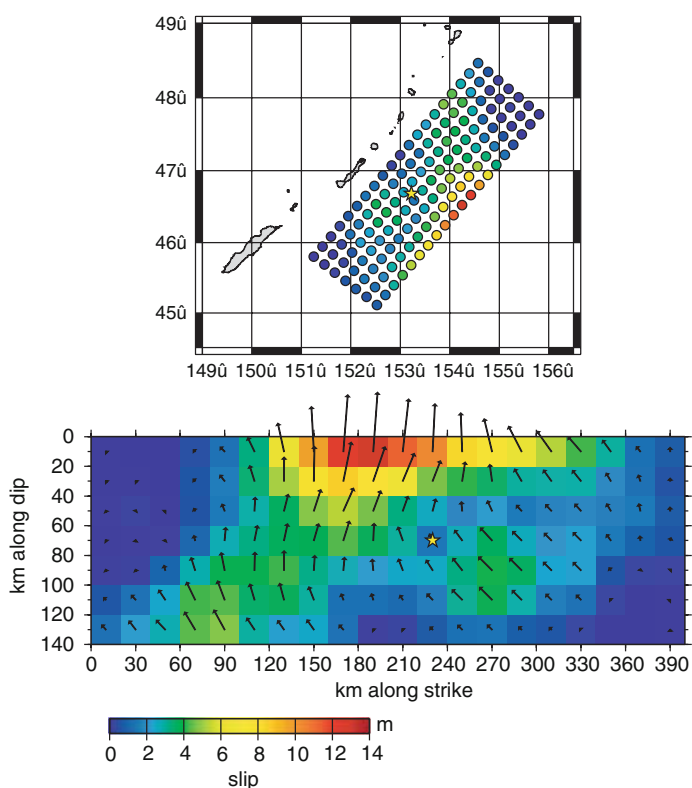

(b)

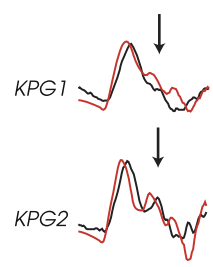
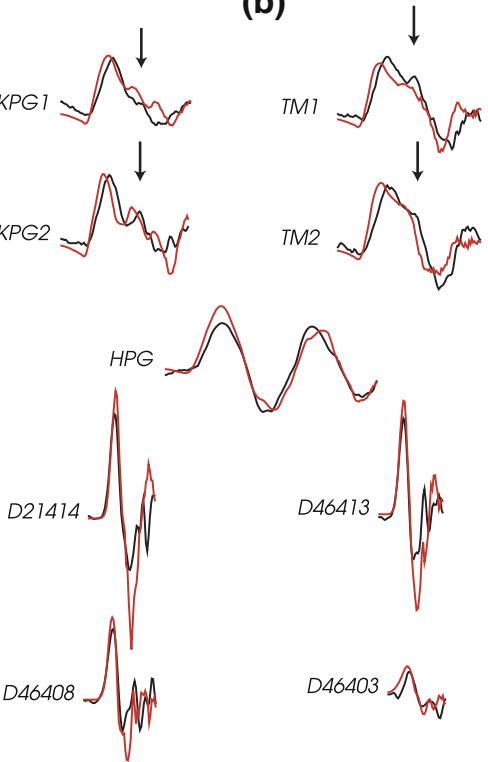

Figure 4

(a) Cumulative slip distribution of the 2006 Kuril earthquake estimated from the combined inversion of $\mathrm{P}$ waves and long-period surface waves. The colour shows the slip amount and arrows represent the motion of hanging wall relative to footwall. The star denotes the hypocenter. (b) Comparison of the deep-ocean tsunami waveforms. Black and red lines show the observed and predicted tsunami waveforms, respectively, with the latter calculated from the slip model shown in (a). The small second peaks on the tsunami record (shown by arrows) are produced by the simulation.

about $5.33 \times 10^{21} \mathrm{Nm}$. The VR values of $58 \%$ and $84 \%$ are obtained for the $\mathrm{P}$ wave and the surface waves, respectively, for this model. This indicates that the waveform fitting of the surface waves is much improved without a substantial deterioration of the P-wave fit (Table 2).

In Figure $4 b$, we compare the observed tsunami waveforms with the predicted ones from the source model. For KPG1, KPG2, TM1, and TM2, the tsunami waveforms match the observations better than the simulation derived from the inversion based on $\mathrm{P}$ waves only. The maximum amplitudes are well retrieved and the waveforms are very similar to the observed waveforms. The small peaks in the first tsunami wave (shown by arrows in Fig. 4b) are also seen in the simulated tsunami waves. However, for these BPRs the calculated tsunami waveforms appear to arrive about 2 min earlier than the observed waveforms. This may indicate that the accuracy of the bathymetric data is insufficient to predict the tsunami travel times. To reach the Japanese stations, the first tsunami waves propagate along the Kuril trench, where rapid changes in seafloor topography may not be accurately represented in the bathymetry data. The accuracy of the bathymetric data will 
be discussed below. The timing of the maximum peaks and period of the tsunami waveform are better predicted in the simulation for the D21414, D46413, D46408 and D46403. However, the first draw-downs following the maximum peaks on the computed tsunami waves are much larger than the observations. The VR of the tsunami waveforms is $73 \%$, which is better than the result using only the $\mathrm{P}$ waveforms.

\subsection{Inversion of Seismic P-Waves, Surface Waves, and BPR Tsunami Waveforms}

All the data, the $\mathrm{P}$ wave, the long-period surface wave and the BPR tsunami waveforms, were finally inverted to estimate our preferred source model for the 2006 Kuril earthquake (Fig. 5a). The pattern of the cumulative slip distribution does not change from the result of the $\mathrm{P}$ and surface wave inversion, while the slip amount is slightly decreased. The maximum slip was estimated to be $11.8 \mathrm{~m}$ in the shallowest subfault near the trench. The total moment is $5.01 \times 10^{21} \mathrm{Nm}$, which is equivalent to $\mathrm{M}_{\mathrm{w}}$ 8.4. The VR of the $\mathrm{P}$ and surface waves are still good, at $58 \%$ and $84 \%$, respectively. The

(a)
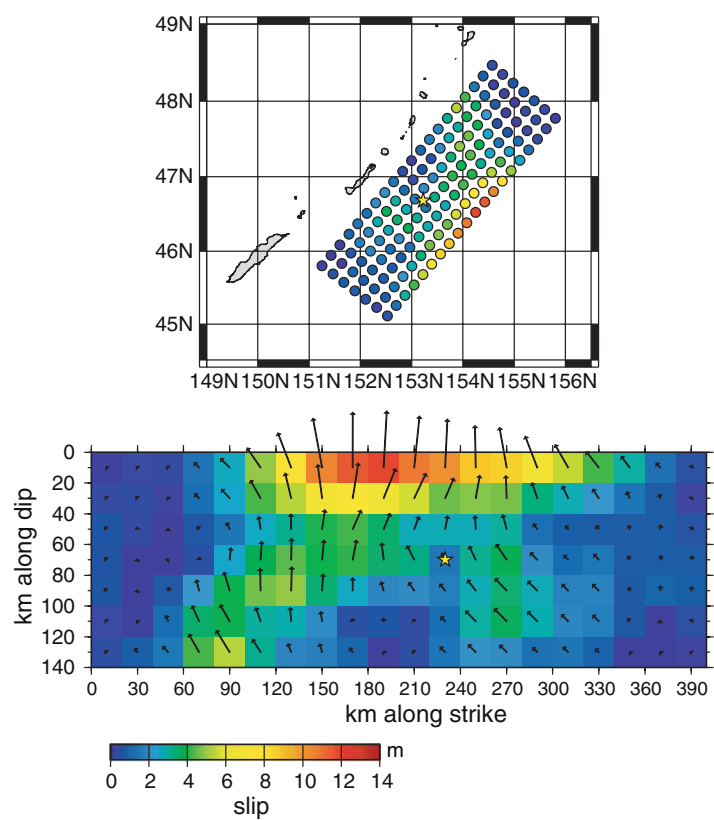

(b)<smiles>CC=CC=CC</smiles><smiles>NC=CC1CC1</smiles>

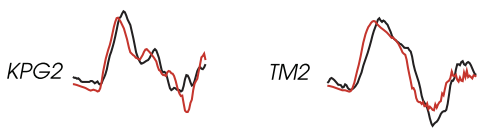

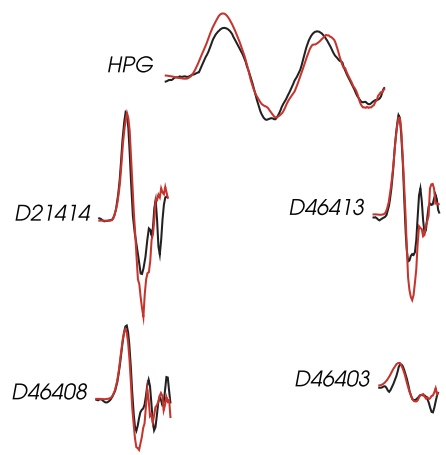

Figure 5

(a) Cumulative slip distribution of the 2006 Kuril earthquake estimated from the simultaneous inversion of $\mathrm{P}$ waves, long-period surface waves and tsunami. The colour shows the slip amount and arrows represent the motion of hanging wall relative to footwall. The star denotes the hypocenter. (b) Comparison of the deep-ocean tsunami waveforms. Black and red lines show the observed and calculated tsunami waveforms respectively, with the latter calculated from the slip model shown in (a). 
offshore tsunami waves are also reproduced well, especially at DART stations, where the computed amplitude, timing and period of tsunami waveforms adequately fit the observations (Fig. 5b). The VR of the tsunami waveforms is better (81\%) than obtained above, which is obviously due to the fact that the tsunami waveforms were inverted together with the seismic waves. A comparison of observed and calculated the $\mathrm{P}$ and surface waves are shown in Figure 6.

\section{Discussion}

Models for the slip distribution of the 2006 Kuril earthquake obtained in recent studies (Fuji and SAtake, 2008; Ji, 2007; Ammon et al., 2008; YAGI, 2006; and YAMANAKA, 2006) are summarized in Table 3. Except for YAGI (2006), all of the models indicate that most of the fault slip occurred over an area that extends from about $100 \mathrm{~km}$ east to $200 \mathrm{~km}$ northeast of the hypocenter (see, e.g., Fig. 4). The seismic models of $\mathrm{J}_{\mathrm{I}}$ (2007), YAmANAKa (2006), and this study all exhibit pronounced peaks in slip about $100 \mathrm{~km}$ due east of the hypocenter, while the tsunami model of Fujii and Satake and the seismic model of AMmON et al. (2008) each show a less peaked slip distribution, with maximum slip located about $200 \mathrm{~km}$ northeast of the hypocenter. The models exhibit considerable variation in maximum slip and seismic moment.

The main differences between the slip pattern obtained here and in the other recent studies are the pronounced peak in slip $100 \mathrm{~km}$ east of the hypocenter and the high seismic moment, of over $5 \times 10^{21} \mathrm{Nm}$. We found that increased smothing in our inversion resulted in models similar to those of FuJII and SATAKE (2008) and Ammon et al. (2008), having a considerably reduced maximum slip. This increase in smoothness, however, came at the expense of a poorer fit to the Love waves used in our inversion. We note that Love waves were likewise used in the inversion of JI (2007), which also had a sharp peak in slip $100 \mathrm{~km}$ east of the hypocenter, but were not used in AMmon et al. (2008), whose model was not sharply peaked. Also, 1-D velocity models with decreasing rigidity at shallow depth were used to convert from moment to slip in this study and that of JI (2007), which would amplify slip at shallow depth where these studies exhibit sharp peaks in slip, compared to the constant rigidity used in the model of AMMON et al. (2008).

While the seismic models of Ji (2007) and Ammon et al. (2008) have moments higher (18\% and $39 \%$, respectively) than the GlobalCMT value of $3.3 \times 10^{21} \mathrm{Nm}$ (http:// www.globalcmt.org), the moment obtained here is even more so-by over $50 \%$. The high moment of our model relative to these other seismic models is due to the fact that we assumed a relatively shallow fault dip, based on the seismic survey of NAKANISHI et al. (2004). The well-known trade-off of dip with seismic moment (KANAMORI and Given, 1981) accounts for an increase in our estimated seismic moment of $46 \%$ over the GlobalCMT fault model with $15^{\circ} \mathrm{dip}$. This trade-off also explains why the larger dip used in YAMANAKA (2006) has resulted in a seismic moment 35\% less than the GlobalCMT result. On the other hand, the tsunami model of FujII and SATAKE (2008) appears to have a 


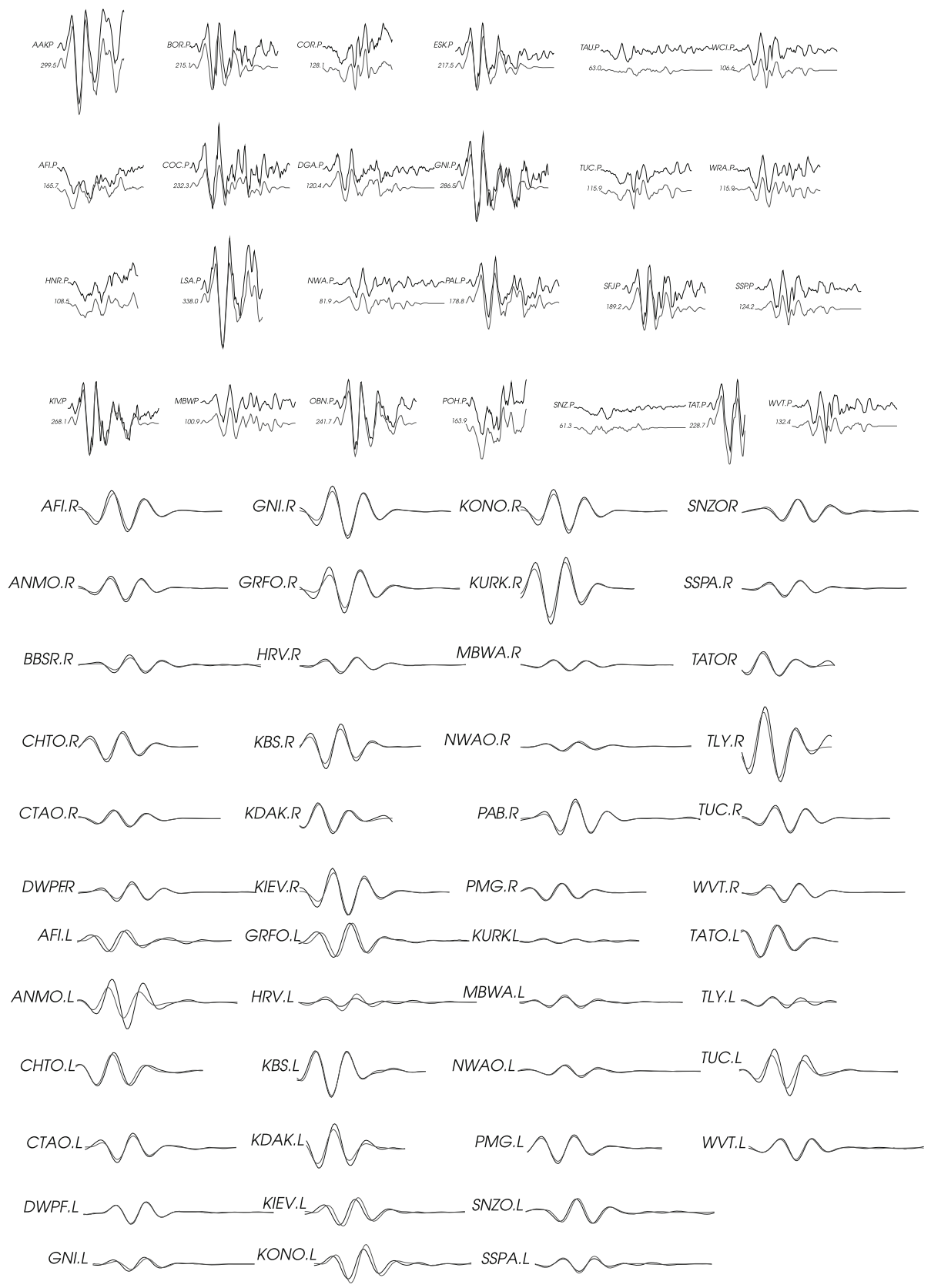

Figure 6

Comparison between observed (black) and calculated (red) waveforms for all seismic waves used in the simultaneous inversion for the 2006 Kuril earthquake. Station names and components (P: P wave, R: Rayleigh wave, L: Love wave) are shown. 
Table 3

A comparison of models of fault slip for the 2006 Kuril earthquake estimated by recent studies

\begin{tabular}{llllll}
\hline Study & Strike $\left(^{\circ}\right)$ & Dip $\left(^{\circ}\right)$ & $\begin{array}{l}\text { Depth } \\
(\mathrm{km})\end{array}$ & $\begin{array}{l}\text { Max. } \\
\text { Slip }(\mathrm{m})\end{array}$ & $\begin{array}{l}\text { Moment } \\
\left(\times 10^{21} \mathrm{Nm}\right)\end{array}$ \\
\hline FuJII and SATAKE (2008) & 214 & 15 & $5-31$ & 6.8 & 2.0 \\
& 214 & $8-15$ & $5-24$ & 7.4 & 2.5 \\
JI (2007) & 220 & 15 & $8-40$ & 9 & 3.9 \\
AMMON et al. (2008) & 215 & 15 & $17-52$ & 7 & 4.6 \\
YAGI (2006) & 214 & 15 & $2-36$ & 7.7 & 1.6 \\
YAMANAKA (2006) & 220 & 25 & $5-30$ & 12.6 & 2.1 \\
This study: P and surface wave P, & 220 & 10 & $17-42$ & 12.8 & 5.3 \\
$\quad$ surface wave, and BPR & 220 & 10 & $17-42$ & 11.8 & 5.1 \\
\hline
\end{tabular}

seismic moment considerably less than the GlobalCMT value-40\% less for the constant dip case, even though it has the same dip as the GlobalCMT solution. We speculate that this may be due to the large subfaults $(50 \mathrm{~km} \times 50 \mathrm{~km})$ used in this model, which have resulted in appreciable slip at shallow depth-about $5 \mathrm{~m}$ at $5 \mathrm{~km}$ depth. Since our fault model allows slip to be concentrated at greater depth, it can accommodate the higher slip required for agreement with the seismic data without resulting in an overprediction of the tsunami amplitude (since slip at greater depth is less efficient at generating a tsunami through seafloor deformation). Finally, we note that an up-dip limit of rupture at 10 $15 \mathrm{~km}$ depth is consistent with the seismogenic zone inferred by NAKANISHI et al. (2004) for the southern Kuril subduction zone, based on the rupture area of the 1973 Nemuro-oki earthquake and thermal constraints on the frictional properties of the Kuril megathrust.

Below we consider other aspects of our slip model for the 2006 Kuril earthquake, including constraints on rupture velocity, the accuracy of bathymetry data for modelling the tsunami data, as well as the possibility that excitation and dispersion of tsunami energy may not be adequately accounted for in our tsunami modelling.

\subsection{Constraints on Rupture Velocity}

The pattern of slip is potentially sensitive to the maximum rupture velocity assumed in the inversion. For a given source duration, fault slip is spread over a wider area when the rupture velocity is high, and it is conversely concentrated when the rupture velocity is low. In order to find the optimal maximum rupture speed of the 2006 Kuril earthquake, we draw curves of VR of the $\mathrm{P}$ and surface waveforms calculated from slip models obtained by varying the maximum rupture speed in a range from $1.5-2.5 \mathrm{~km} / \mathrm{sec}$ (Fig. 7). It is difficult to find the maximum point of the $\mathrm{P}$ and surface wave VR curves, indicating that the seismic data do not constrain the maximum rupture speed well.

We simulated tsunami waveforms derived from the source process obtained by changing the maximum rupture velocity and calculated the VR for the tsunami 


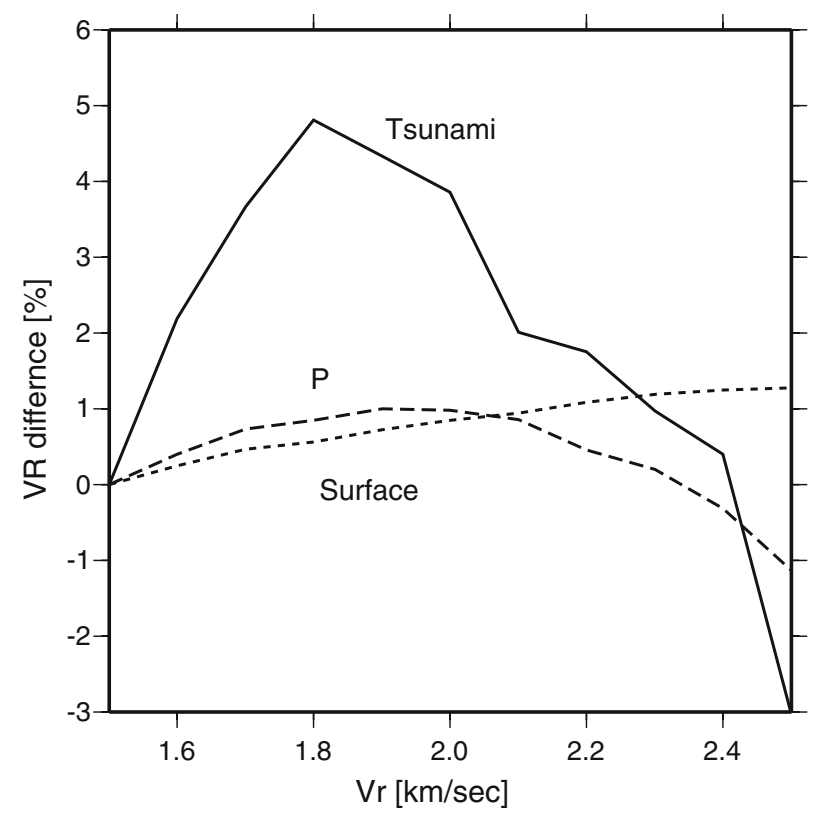

Figure 7

Relationship between variance reductions and the maximum rupture velocity (Vr) for the 2006 Kuril earthquake.

waveforms (Fig. 7). The maximum tsunami VR is successfully found at the maximum rupture speed of $1.8 \mathrm{~km} / \mathrm{sec}$. By itself tsunami data cannot resolve rupture velocity, because rupture speeds are much faster than the velocity of tsunami propagation-the tsunami velocity is only about $0.2 \mathrm{~km} / \mathrm{sec}$ over water depths of $4000 \mathrm{~m}$. However, tsunami data can help resolve rupture velocity when used in conjunction with seismic data, because its sensitivity to the slip pattern can resolve the trade-off in rupture area vs. rupture velocity inherent in the use of teleseismic data. A maximum rupture velocity of $1.8 \mathrm{~km} / \mathrm{sec}$ was therefore applied for all inversions for the 2006 Kuril earthquake.

\subsection{Accuracy of Bathymetric Data}

Tsunami in the deep-ocean propagates at a velocity proportional to the square root of ocean depth. Although the GEBCO bathymetric dataset used for the tsunami calculations presented above is gridded at 1', the resolution of the original bathymetric soundings used to construct the grid can be much sparser. Especially near rapid changes in seafloor topography such as ocean trenches, gridded bathymetry data sets such as GEBCO may include significant errors in bathymetry. Even though deep-ocean tsunami calculations are less sensitive to errors in bathymetry, such errors gradually accumulate in tsunami calculations over long distances, and may result in a difference in tsunami waveforms in 
Table 4

Comparison of water depths at the BPRs used in this study

\begin{tabular}{llll}
\hline & OBPG $(\mathrm{m})$ & GEBCO $(\mathrm{m})$ & \multicolumn{1}{l}{$\begin{array}{l}\text { Difference }(\mathrm{m}) \\
\text { (OBPG-GEBCO) }\end{array}$} \\
\hline KPG1 & & +61 \\
KPG2 & 2279 & 2218 & +23 \\
THK1 & 2233 & 2210 & 0 \\
THK2 & 1563 & 1563 & -53 \\
HPG1 & 954 & 1007 & +420 \\
D21414 & 756 & -200 \\
D46413 & 1176 & 5511 & -60 \\
D46408 & 5311 & 5632 & +130 \\
D46402 & 5572 & 5242 & -21 \\
D46403 & 5372 & 4732 & +26 \\
D51407 & 4711 & 4484 & 0 \\
\hline
\end{tabular}

far-field. We here discuss the accuracy of the bathymetric data used in our tsunami calculation.

The ocean bottom pressure is an independent measurement for the water depth, which can be inferred from the hydrostatic condition expressed by $\mathrm{P}=\rho \mathrm{gh}$, where $\mathrm{P}$ is ocean bottom pressure, $\rho$ is density of water, $\mathrm{g}$ is gravitational acceleration and $\mathrm{h}$ is water depth. We here compare the water depths observed at BPRs and included in the GEBCO bathymetric dataset used in the tsunami calculation in Table 4. The water depths measured by BPRs are consistent with the GEBCO data set at several sites. Especially at THK1 and D51407, the differences are less than $1 \mathrm{~m}$. However, significant differences of more than $100 \mathrm{~m}$ in the water depth are seen at three sites. The maximum difference reaches $420 \mathrm{~m}$ at station HPG1 located near a small island (Hatsushima), where the seafloor topography is complicated. A comparison of high-resolution swath bathymetry data around the Japan Trench surveyed by the Japan Agency for Marine-Earth Science and Technology with the GEBCO dataset shows a systematic discrepancy up to $600 \mathrm{~m}$ along the Japan Trench axis (Fig. 8). The GEBCO bathymetric dataset was used for the far-field tsunami calculation in the finite-difference scheme because it covers the whole Earth with uniform gridding space. However, such a global dataset may not accurately represent rapid changes of topography that occur in areas such as ocean trenches.

The Kuril trench axis is also a region where bathymetry changes rapidly and which the tsunami must pass over in order to arrive at the Japanese BPRs. We do here a trial calculation of the tsunami travel times to estimate whether an error in the bathymetric data could explain the observed difference in tsunami travel time. Tsunami propagation speed is expressed by square root of gh, which is $264 \mathrm{~m} / \mathrm{sec}$ over the trench axis, assuming an average water depth of $7000 \mathrm{~m}$. We next suppose that the water depth is deeper by $600 \mathrm{~m}$, based on the comparison with the high-accuracy sea beam data, that is $7600 \mathrm{~m}$, and the tsunami speed becomes $275 \mathrm{~m} / \mathrm{sec}$. The distance from the epicenter of the 2006 Kuril earthquake to KPG1 is about $900 \mathrm{~km}$. This difference in the water depths 
(a)

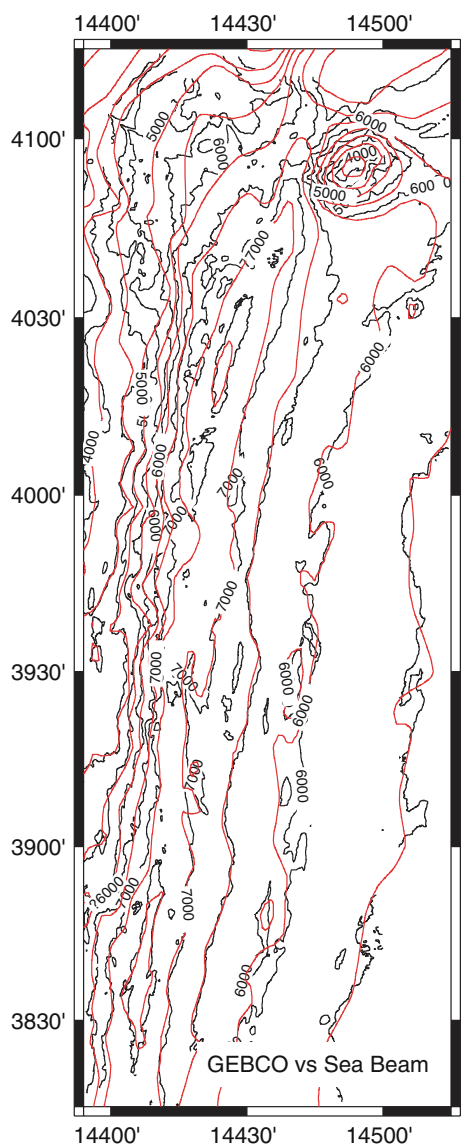

$-1000$ (b)

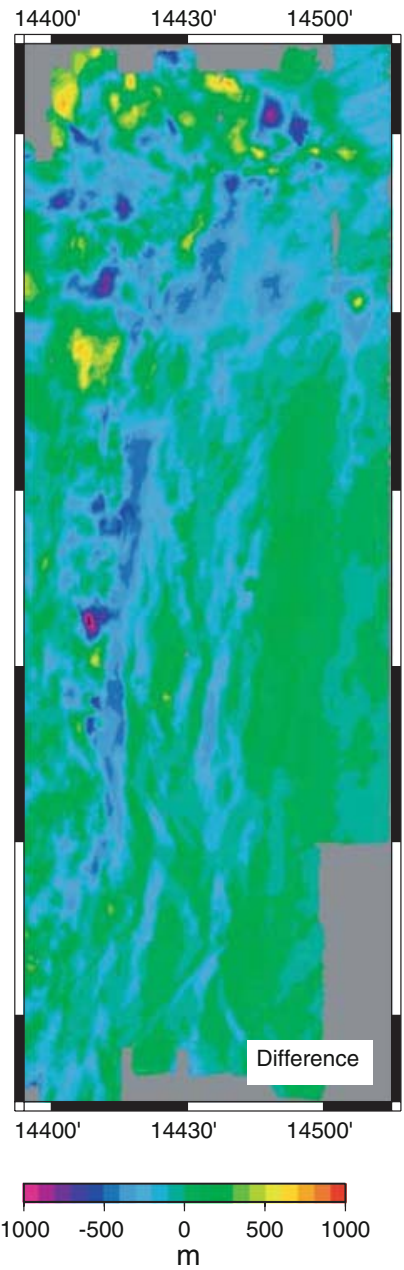

Figure 8

(a) Comparison of the GEBCO bathymetric dataset (red contours) and the high-resolution swath bathymetry data (black contours) around the Japan Trench. (b) The difference between GEBCO and the swath dataset.

produces a difference in the tsunami travel times of about 2 and half minutes at KPG1. As shown in Figure $5 b$, the calculated tsunami waveforms appear shifted in time by $2-3$ minutes earlier than the waveforms observed on the Japanese BPRs, which would be consistent with a bathymetry error of $600 \mathrm{~m}$ along the Kuril Trench. Thus, the discrepancy in observed and calculated tsunami arrival times for BPRs along the Japanese coast may be due to water depths along the Kuril trench axis that are shallower by several hundreds meters on average than the bathymetric dataset we used in the tsunami calculation. 


\subsection{Initial Sea-surface Elevation and Tsunami Waveform Dispersion}

As discussed in TANIOKA et al. (2008) and RABINOVICH et al. (2008), the procedure used here to calculate the initial sea-surface elevation, which assumes it is identical to the vertical coseismic displacement of the sea floor, is not valid for small-scale sources in deep water. This issue can be addressed by either applying the technique of KAJIURA (1963) to smooth the spatial pattern of seafloor displacement, or by numerically simulating the three-dimensional hydrodynamical response of the ocean to a sudden shift in the seafloor. RABINOVICH et al. (2008) adopted the latter approach when computing tsunami from both the 2006 Kuril earthquake considered here and a later Kuril event which occurred on 13 January 2007. As shown in RABINOvich et al. (2008, Fig. 6), while the three-dimensional simulation of tsunami excitation makes a dramatic difference in the pattern of initial seasurface displacement for the 2007 earthquake, it makes less difference for the 2006 event considered here. Although in the latter case a sharp maximum in seafloor displacement is reduced from 2.7 to $1.9 \mathrm{~m}$, the broader pattern of seafloor displacement is relatively unchanged. As pointed out by TANIOKA et al. (2008), the dramatic difference in the tsunami excitation between the two events is due to the considerably narrower pattern of seafloor deformation produced by the 2007 earthquake. Unlike the 2006 event, which occurred on the shallowly dipping megathrust of the Kuril subduction zone, the 2007 event occurred on a steeply-dipping fault in the oceanic plate near the outer rise. This difference in fault dip results in a projection of the fault slip area onto the seafloor which is much narrower for the 2007 event than for the 2006 event (approximately $30 \mathrm{~km}$ and over $60 \mathrm{~km}$, respectivelysee Figs. 6a and 6b of Rabinovich et al., 2008). Although the result of RABinovich et al. (2008) suggests the seafloor deformation pattern of the 2006 Kuril earthquake is close to the limit at which the assumption that this pattern is identical to the initial sea-surface elevation breaks down, our success in modelling the resulting tsunami using the seismic model suggests it is still a reasonable approximation for this event.

The same reasoning suggests that dispersion of tsunami energy is less a concern for the tsunami generated by the 2006 Kuril earthquake than for that generated by the 2007 event. Figure 9 illustrates spectragrams for the two tsunami's, both recorded at BPR D21414. Figure 9a shows that most of the tsunami energy recorded for the 2006 event is confined to the $0-2 \mathrm{mHz}$ frequency band, arriving between 7500 and 8250 seconds after the earthquake. The energy arriving within this bandwidth exhibits little dispersion, consistent with the dispersion curve indicated in the figure: the latter is steep in the $0-2 \mathrm{mHz}$ band, predicting only small dispersion. The spectragram for the 2007 event (Fig. 9b), on the other hand, shows that much of the tsunami energy recorded for this event extends through the frequency band $0-3 \mathrm{mHz}$, and dispersion in the energy above $2 \mathrm{mHz}$ is evident (again, consistent with the dispersion curve). The wider area of the seafloor elevated by the 2006 event due to its occurrence on the shallowly-dipping megathrust has excited lower frequency tsunami energy that is little affected by dispersion, while the narrow area of sea floor elevated by the 2007 outer rise event on a steeply-dipping fault has excited higher frequency tsunami energy that is affected by dispersion. 
(a) 2006 Kuril Event

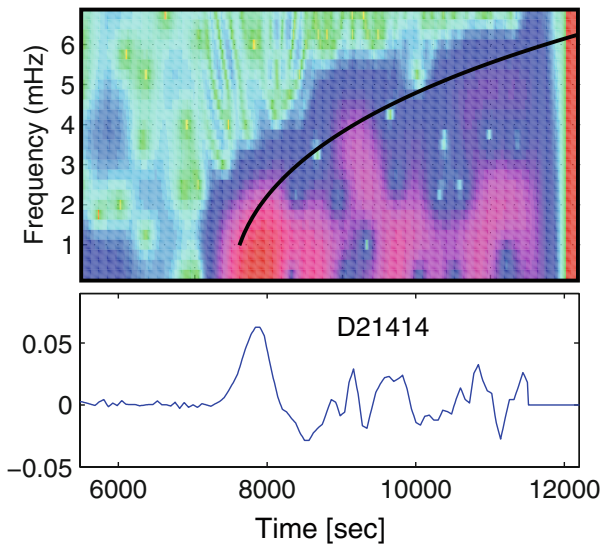

(b) 2007 Kuril Event

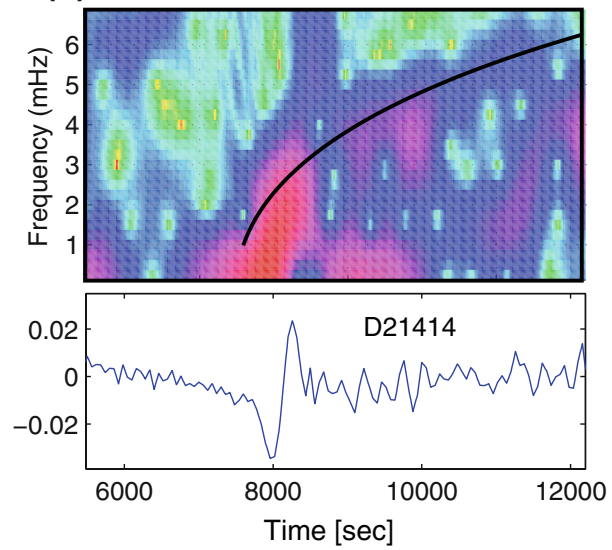

Figure 9

Spectrograms calculated using waveform data from BPR D21414 for: (a) The 15 November, 2006 Kuril earthquake, and (b) the 13 January 2007 Kuril Earthquake. Approximate dispersion curves calculated for $6000 \mathrm{~m}$ water depth are indicated.

\subsection{Implications for Teletsunami Forecasting}

According to the result shown in Figs. 3 and 4 of the 2006 Kuril earthquake, the slip model derived using only $\mathrm{P}$ waves is clearly different from the slip model of $\mathrm{P}$ and longperiod surface waves. There may be several reasons for this inaccuracy in the P-wave slip model. Teleseismic body waves can be very sensitive to fault orientation as well as nearsource structure, including the slope of the seafloor (WIENS, 1987; Окамото and Miyatake, 1989). They can also be affected by large-scale, laterally heterogeneous velocity structure along the path between source and receiver; although this can be removed by aligning observations and synthetics along the P-wave arrival, it is at the expense of any information on absolute position, and the result is therefore dependent on the accuracy of the presumed hypocenter. This study suggests that slip inversions using P-wave data alone can be unstable, in the sense that different models appear to be able to satisfy the data almost equally well. The $\mathrm{P}$ wave only and the $\mathrm{P}$ wave + surface wave slip models obtained above differed substantially in their slip distributions, however while the latter model leads to a substantial $28 \%$ improvement in surface wave VR over the P wave only model, the corresponding reduction of the P-wave VR is only $9 \%$ after including the surface wave data. The inclusions of long-period surface wave data also resulted in a model which gave a much better fit to the BPR tsunami waveforms, resulting in a tsunami VR of $73 \%$, and was able to match subtle features of the tsunami waveforms.

The variance reduction of the teletsunami waveforms can be improved to $81 \%$ with the inclusion of BPR data. However, for the configuration of seismic and BPR platforms available at the time of the earthquakes considered here, this increased accuracy is achieved only at the expense of a significant delay in the acquisition of the data required 
to achieve it. To obtain a source model achieving a 73\% VR in teletsunami data, it took 63 minutes from the initiation of earthquake rupture for the surface and body waves to arrive at the recording stations. In contrast, the first tsunami waveforms did not begin to arrive at the nearest BPR (KPG2 in Fig. 1) until 54 minutes after rupture initiation, the full tsunami waveform used in the inversion was not recorded by this nearest BPR until 134 minutes, and it took 294 minutes for all of the tsunami waveforms useful for inversion of the source to be recorded. While the time it takes for tsunami waveforms to be recorded depends on the location of the earthquake and the BPRs, the larger delay for the tsunami data is fundamentally due to the slower propagation of tsunami vs. seismic waves. Since the processing time needed for the slip inversion is only a few minutes, the larger delay needed to reduce the VR by including BPR data may be important in the context of tsunami warning. On the other hand, because tsunami generation can be enhanced by non-seismic mechanisms such as submarine landslides, BPR data would seem to provide an indispensible check on seismic models of the tsunami source.

\section{Conclusion}

Accurate and rapid forecasts of teletsunami waveforms could potentially be used as part of a tsunami warning system to forecast impacts on coastlines likely to be affected by a tsunami. The potential for such forecasts has been demonstrated for source models inferred from deep-ocean BPRs (TiTov et al., 2005), and the US National Oceanic and Atmospheric Administration is in the process of greatly expanding the network of deepocean BPRs that could be used for this purpose. Less attention has been paid to the use of tsunami source models derived from seismic data, in part because the only data that could be used to validate such models were from coastal tide gauges, and these data can be very sensitive to details of coastal bathymetry that are often poorly known. Since the expansion of the network of deep-ocean BPRs, whose data can be expected to be less sensitive to bathymetry than to details of the tsunami source, it is now possible to validate seismic models of the tsunami source.

The goal of this study was to use the first occurrence of a large tsunamigenic earthquake to be recorded by an extensive network of deep-ocean BPRs in the Pacific Ocean, to test whether seismic data could be used to forecast the teletsunami recorded at the BPRs. Seismic data from the 15 November, 2006 Kuril earthquake were inverted to obtain two candidate models for the spatial distribution of slip on the Kuril megathrust: One model was obtained by inverting only $\mathrm{P}$ waves, and the other used both $\mathrm{P}$ - and longperiod surface waves. Both models forecast teletsunami waveforms that were a reasonable match to the observations, with variance reductions (VRs) of $60 \%$ and $73 \%$, respectively.

The source model obtained using both $\mathrm{P}$ and surface waves, however, produced teletsunami waveforms with a better match to the observations. While P-wave data appear to be sensitive to details of the earthquake rupture process, source inversion using P-wave data alone appears to be less stable than the combined use of P- and 
surface-wave data. We speculate that this instability in the P-wave only inversions may be due to, or at least exacerbated by, sensitivity of the P-wave data to factors that may be either poorly constrained or not well represented in the forward modelling, such as fault orientation and near-source velocity structure. (Although we did not present them in this paper, inversions using $S$ waves indicated that similar considerations apply to them). We conclude that the use of the long-period surface waves with $\mathrm{P}$ waves was very effective in stabilizing the teleseismic inversion and resulted in improving the accuracy of the deep-ocean teletsunami forecasting for the 2006 Kuril earthquake.

Our results have been obtained only for 1 event, which is a megathrust event on the Kuril Trench. Other studies (CHLIEH et al., 2007; AMmON et al., 2006, among many others) likewise suggest that seismic waveform data can be used to obtain reliable slip models for large megathrust events. The situation is not as clear for other, intraplate events which can also be tsunamigenic, including outer rise events such as the 2007 Kuril earthquake as well as the 1933 Sanriku and 1977 Sumba earthquakes. For these and other intraplate earthquakes it is not always clear what the fault orientation is, and this can have a pronounced influence on tsunami generation. Also slip on a steeply dipping fault may result in a narrow pattern of seafloor deformation, for which some assumptions often used in modelling tsunami generation and propagation, in particular the excitation and dispersion discussed in section 4.3, may not be valid. We are investigating these issues using data from the 2007 Kuril earthquake, which was also recorded by numerous of BPRs in the Pacific Ocean. These results will be published in a subsequent, companion paper.

\section{Acknowledgements}

We thank the editor, K. Satake, and the reviewers I. Fine, T. Lay, and A. Rabinovich for their careful and constructive reviews, and also the U.S. National Oceanic and Atmospheric Administration, the Japan Agency for Marine-Earth Science and Technology and Tohoku University for providing BPR data, and the Data Management Center of the Incorporated Research Institutions for Seismology for access to the seismic data used in this study.

\section{REFERENCES}

Ammon, C.J., Ji, C., Thio, H.-K., Robinson, D., Ni, S., Huorleifsdottir, V., Kanamori, H., Lay, T., Das, S., Helmberger, D., Ichinose, G., Polet, J., and Wald, D. (2005), Rupture process of the 2004 Sumatra-Andaman earthquake, Science 308, 1133-1139, doi: 10.1126/science.1112260.

Ammon, C.J., Kanamori, H., Lay, T., and Velasco, A.A. (2006), The 17 July 2006 Java tsunami earthquake, Geophys. Res. Lett. 33, L24308, doi:10.1029/2006GL028005.

Ammon, D.J., Kanamori, H., and Lay, T. (2008), A great earthquake doublet and seismic stress transfer cycle in the central Kuril Islands, Nature, 45, 561-565. 
Bouchon, M. (1976), Teleseismic body wave radiation from a seismic source in a layered medium, Geophys. J. R. Astr. Soc. 47, 515-530.

Briggs, R.W., Sieh, K., Meltzner, A.J., Natawidjaja, D., Galetzka, J., Suwargadi, B., Hsu, Y.-J., Simons, M., Hananto, N., Suprihanto, I., Prayudi, D., Avauac, J.-P., Prawirodirdjo, L., and Bock, Y. (2006), Deformation and slip along the Sunda megathrust in the great 2005 Nias-Simeulue earthquake, Science 311, 1897-1901.

Chlieh, M., Avouac, J.-P., Huorleifsdottir, V., Song, T.-R. A., Ji, C., Sieh, K., Sladen, A., Hebert, H., Prawirodurdjo, L., Bock, Y., and Galetzka, J. (2007), Coseismic slip and afterslip of the Great $M_{w} 9.15$ Sumatra-Andaman Earthquake of 2004, Bull. Seismol. Soc. Am. 97, S152-S173, doi:10.1785/0120050631.

Delouis, B., Giardini, D., Lundgren, P., and Salichon, J. (2002), Joint inversion of InSAR, GPS, teleseismic, and strong-motion data for the spatial and temporal distribution of earthquake slip: Application to the 1999 Izmit main shock, Bull. Seis. Soc. Am. 92, 278-299.

Eкström, G., Tromp, J., and Larson, E.W.F. (1997), Measurements and global models of surface wave propagation, J. Geophys. Res. 102(B4), 8137-8157.

FujI, Y. and Satake, K. (2008), Tsunami sources of the November 2006 and January 2007 great Kuril earthquakes, Bull. Seismol. Soc. Am, 98, 1559-1571.

Geist, E. L. and Dmowska, R. (1999), Local tsunamis and distributed slip at the source, Pure Appl. Geophys. $154,485-512$.

HaRtzell, S. H. and Heaton, T. H. (1983), Inversion of strong ground motion and teleseismic waveform data for the fault rupture history of the 1979 Imperial Valley, California, earthquake, Bull. Seismol. Soc. Am. 73, 1553-1583.

Hartzell, S., and LANGer, C. (1993), Importance of model parameterization in finite fault inversions; application to the $1974 M_{w} 8.0$ Peru earthquake, J. Geophys., Res., 98, 22,123-22,134.

Hirata, K., Aoyagi, M., Mikada, H., Kawaguchi, K., Kaiho, Y., Iwase, R., Morita, S., Fujisawa, I., Sugioka, H., Mitsuzawa, K., Suyehiro, K., Kinoshita, H., and Fujiwara, N. (2002), Real-time geophysical measurements on the deep seafloor using submarine cable in the southern Kurile subduction zone, IEEE J. Oceanic Eng., 27, $170-181$.

Hirata, K., Takahashi, H., Geist, E., Satake, K., Tanioka, Y., Sugioka, H., and Mikada, H. (2003), Source depth dependence of small-tsunamis recorded with ocean-bottom pressure gauges: The January 28, $2000 \mathrm{Mw}$ 6.8 earthquake off Nemuro Peninsula, Japan, Earth Planet. Sci. Lett. 208, 305-318.

Ichinose, G. A., Somerville, P., Thio, H. K., Matsushima, S., and SAto, T. (2005), Rupture process of the 1948 Fukui earthquake (M 7.1) from the joint inversion of seismic waveform and geodetic data, J. Geophys. Res. 110, doi:10.1029/2004JB003437.

Imase, R., Asakawa, K., Mikada, H., Goto, T., Mitsuzawa, K., Kawaguchi, K., Hirata, K. and Kaino, Y. (2003), Off Hatsushima Island observatory in Sagami Bay: Multidisciplinary long-term observation at cold seepage site with underwater mateable connectors for future use, Proc. 3rd International Workshop on Scientific Use of Submarine Cables and Related Technologies, pp 31-34.

Ji, C. (2007), Rupture process of the 2006 Nov. 15 Magnitude 8.3 Kuril Island earthquake, http:// earthquake.usgs.gov/eqcenter/eqinthenews/2006/usvcam/fite_fault.php,

Johnson, J. M., Satake, K., Holdahl, S. R. and Sauber, J. (1996), The 1964 Prince William Sound earthquake: Joint inversion of tsunami and geodetic data, J. Geophys. Res. 101(B1), 523-532.

KaJiura, K. (1963), The leading wave of a tsunami, Bull. Earthq. Res. Inst. 41, 535-571.

KANAMORI, H. and GIVEN, J. W. (1981), Use of long-period surface waves for rapid determination of earthquakesource parameters, Phys. Earth Planet. Inter. 27, 8-31.

Kanamori, H. and Stewart, G.S. (1976), Mode of the strain release along the Gibbs fracture zone, Mid-Atlantic ridge, Phys. Earth Planet. Int. 11, 312-335.

Kanazawa, T. and Hasegawa, A. (1997), Ocean-bottom observatory for earthquakes and tsunami off Sanriku, north-east Japan using submarine cable, Paper presented at International Workshop on Scientific Use of Submarine Cable, Inst. of Electr. and Electr. Eng., Okinawa, Japan.

Kikuchi, M. and Kanamori, H. (1991), Inversion of complex body waves-III, Bull. Seismol. Soc. Am. 81, 23352350.

KoKETSu, K., Hikima, K., MiYAZAKI, S., and IDE, S. (2004). Joint inversion of strong motion and geodetic data for the source process of the 2003 Tokachi-oki, Hokkaido, earthquake, Earth Planets and Space 56, 329-334.

Konca, A. O., Huorleifsdottir, V., Song, T.-R. A., Avouac, J.-P., Helmberger, D. V., Ji, C., Sieh, K., Briggs, R., and MeltZner, A. (2007), Rupture kinematics of the $2005 M_{w} 8.6$ Nias-Simeulue earthquake from the joint inversion of seismic and geodetic data, Bull. Seismol. Soc. Am. 97, S307-S322. 
Lawson, C. L. and Hanson, R. J. Solving Least-squares problems, 340 pp., (Prentice-Hall, Series in Automatic Computation, 1974).

Matsumoto, K., TakaneZawa, T., and OoE, M. (2000), Ocean tide models developed by assimilating TOPEX/ POSEIDON altimeter data into hydrodynamical model: A global model and a regional model around Japan, J. Oceanogr. 56, 567-581.

Nakanishi, A., Smith, A. J., Miura, S., Tsuru, T., Kodaira, S., Obana, K., Takahashi, N., Cummins, P.R., and KANEDA, Y. (2004), Structural factors controlling the coseismic rupture zone of the 1973 Nemuro-Oki earthquake, the southern Kuril Trench seismogenic zone, J. Geophys. Res. 109, doi:10.1029/2003JB002574.

OкADA, Y. (1985), Surface deformation due to shear and tensile faults in a half space, Bull. Seismol. Soc. Am. 75, 1135-1154.

Окамото, Т. and Мiуатаке, Т. (1989), Effects of near source seafloor topography on long-period teleseismic P waveforms, Geophys. Res. Lett. 11, 1309-1312.

Rabinovich, A. B., Lobkovsky, L. I., Fine, I. V., Thomson, R. E., Ivelskaya, T. N., and Kulikov, E. A. (2008), Near-source observations and modeling of the Kuril Islands tsunamis of 15 November 2006 and 13 January 2007, Adv. Geosci. 14, 105-116.

SATAKE, K. (1987), Inversion of tsunami waveforms for the estimation of a fault heterogeneity: Method and numerical experiments, J. Phys. Earth 35, 241-254.

SATAKE, K. (1993), Depth distribution of coseismic slip along the Nankai Trough, Japan, from joint inversion of geodetic and tsunami data, J. Geophys. Res. 98, 4553-4565.

SATAKE, K. (1995), Linear and nonlinear computations for the 1992 Nicaragua earthquake tsunami, Pure Appl. Geophys., 144, 455-470.

Satake, K. and Tanioka, Y. (1995), Tsunami generation of the 1993 Hokkaido Nansei-Oki earthquake, Pure Appl. Geophys. 144, 803-821.

Stein, S. and Okal, E. A. (2007), Ultralong period seismic study of the December 2004 Indian Ocean Earthquake and implications for regional tectonics and subduction process, Bull. Seismol. Soc. Am. 97, S279-S295.

TANIOKA, Y., SATAKE, K., and RuFF, L. (1995), Total analysis of the 1993 Hokkaido Nansei-Oki earthquake using seismic wave, tsunami, and geodetic data, Geophys. Res. Lett. 22(1), 9-12.

Tanioka, Y., Hasegawa, Y., and Kuwayama, T. (2008), Tsunami waveform analysis of the 2006 underthrust and 2007 outer-rise Kurile earthquakes, Adv. Geosci. 14, 129-143.

Thio, H. K., Graves, R. W., Somerville, P. G., Sato, T., and IshiI, T. (2004), A multiple time window rupture model or the 1999 Chi-Chi earthquake from a combined inversion of teleseismic, surface wave, strong motion, and GPS data, J. Geophys. Res. 109, B08309, doi:10.1029/2002JB002381.

Titov, V.V., González, F.I., Bernard, E.N., Eble, M.C., Mofjeld, H.O., Newman, J.C., and Venturato, A.J. (2005), Real-time tsunami forecasting: Challenges and solutions. Nat. Hazards 35(1), Special Issue, U.S. National Tsunami Hazard Mitigation Program, 41-58.

WIENS, D.A. (1987), Effects of near source bathymetry on teleseismic P waveforms, Geophys. Res. Lett. 14, $761-764$.

YAGI, Y. (2006), Fault rupture imaging of the Nov. 15, 2006 earthquake that occurred off Chishima, http:// www.geo.tsukuba.ac.jp/press_HP/yagi/EQ/Chishima/ (in Japanese).

YamanaKa, Y. (2006), Earthquake note No. 183, http://www.eri.u-tokyo.ac.jp/sanchu/Seismo_Note/2006/ EIC183.html (in Japanese).

(Received April 14, 2008, revised September 1, 2008)

To access this journal online:

www.birkhauser.ch/pageoph 